\section{A Ripening Index for Banana Fruit Based on Starch Content}

\author{
Sylvia M. Blankenship', \\ Donna D. Ellsworth ${ }^{2}$, and \\ Ronald L. Powell ${ }^{3}$
}

Additional index words. Musa (AAA group Cavendish Subgroup) 'Grand Nain', ethylene, soluble solids, quality, postharvest physiology, maturity.

Summary. A starch staining technique using pictures to rate starch disappearance has been developed to determine banana pulp maturity. The disappearance of starch from the pulp shows linear correlation with peel color $\left(r^{2}=0.76\right)$ and soluble solids content $\left(r^{2}=0.81\right)$. Pulp pH shows a poor correlation with starch disappearance $\left(r^{2}=0.38\right)$. Staining banana pulp starch with an iodine solution is a quick and easy method for estimation of pulp maturity.

$\mathrm{T}$ raditionally, banana maturity has been judged by the amount of peel chlorophyll and its visual disappearance with ripening. Peel color charts have been developed to help standardize banana maturity ratings for industry and research purposes (Chiquita Brands, n.d.; Von Loesecke, 1950). High ripening temperatures (Charles and Tung, 1973) and low relative humidities (Haard and Hultin, 1969) often can make bananas retain chlorophyll, creating a

${ }^{1}$ Associate Professor, Department of Horticultural Science, North Carolina State University, Raleigh, NC 27695

${ }^{2}$ Former Research Technician, Department of Horticultural Science, North Carolina State University, Raleigh, NC 27695

${ }^{3}$ Chiquita Brands, Inc., 250 East Fifth St., Cincinnati, OH 45202. Present address: 6549 Amelia Dr., Cincinnati, $\mathrm{OH} 45241$.

This work was supported (in part) by the North Carolina Agricultural Research Service and Chiquita Brands, Inc. Mention of a trademark or proprietary product does not constitute a guarantee or warranty of the product by the North Carolina Agricultural Research Service nor the USDA and does not imply its approval to the exclusion of other products that may also be suitable. situation in which peel color does not reflect internal changes. An internal indicator of ripeness can provide additional information on the advancement of maturity. Carbohydrate and respiratory changes during ripening have been studied extensively (Beaudry, et al., 1989; Hubbard, et al., 1990; Von Loesecke, 1950). However, a rapid, simple method to assess pulp starch conversion has not been published to the best of our knowledge.

Iodine staining of starch has been used to help judge maturity in apples and pears (North, 1961; Saltveit and Hale, 1982). We adapted this tech- nique, developing a starch iodine staining chart for bananas and then correlated starch disappearance with peel color, soluble solids, and $\mathrm{pH}$ in normally ripening bananas.

Green 'Grand Nain' bananas (Musa AAA group Cavendish subgroup) were obtained from a commercial source. Hands were cut into individual green fruit, which were then gassed with 150 to $200 \mu \mathrm{l}$ ethylene/ liter at $>80 \% \mathrm{RH}$ at $20 \mathrm{C}$ for $24 \mathrm{~h}$, and then held at $14.4 \mathrm{C}$ for ripening. The starch chart was developed over $\approx 6$ months using many different lots of bananas and by drawing patterns of

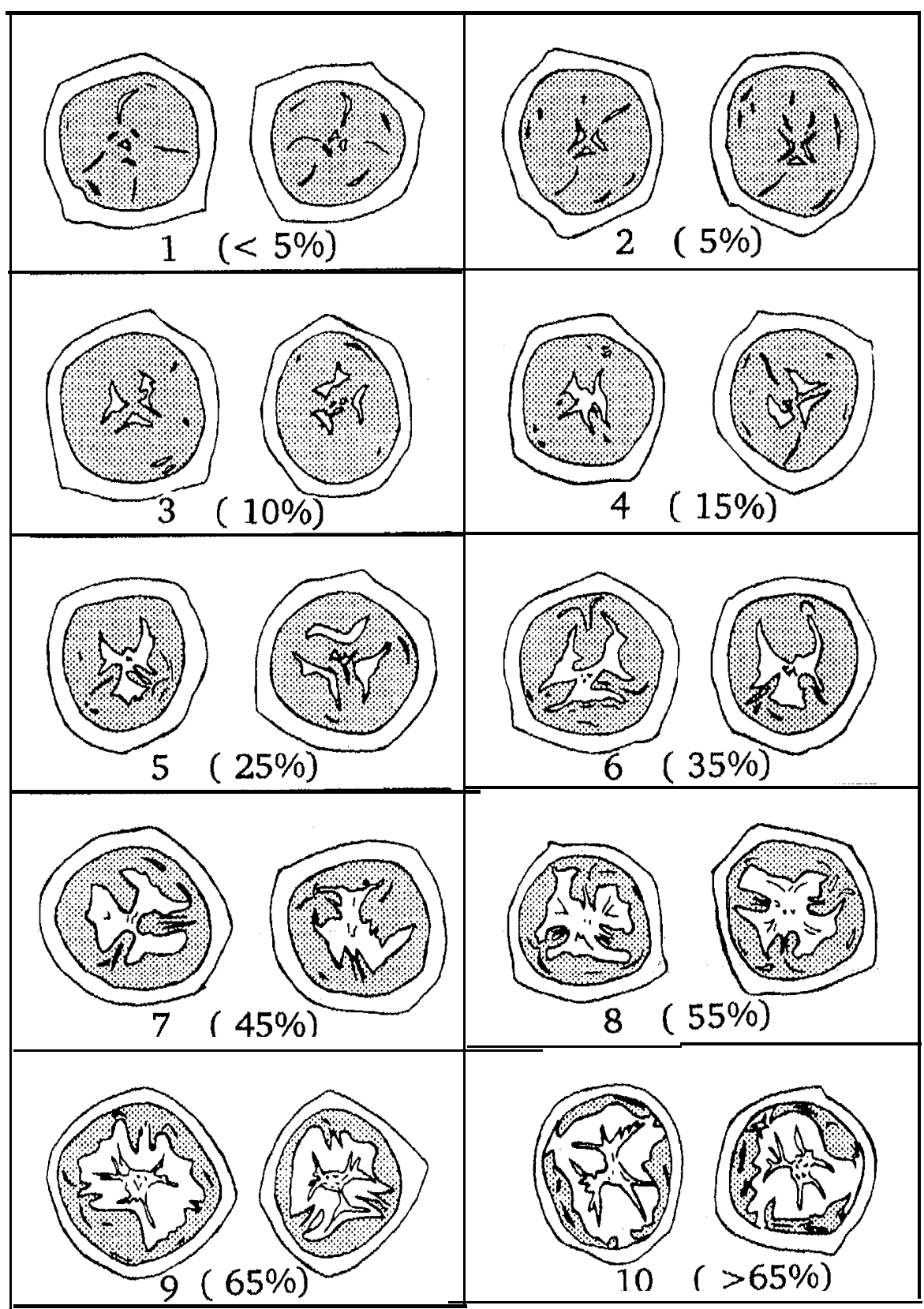

Fig. 1. Starch content patterns of ripening banana stained with an iodine solution. Bracketed percentages refer to area of unstained pulp. 
the stained fruit. Drawings were grouped, and 10 distinguishable stages were determined. Each set of representative pictures was assigned a rating number (1-10) based on the percentage ofunstained area. Either the rating number or percentage of unstained area could be used in banana evaluation.

Both $\mathrm{pH}$ and soluble solids were measured. Because it is difficult to press any liquid from a banana, $10 \mathrm{~g}$ of pulp taken from a transverse crosssection removed at the midpoint of the long axis of the fruit was placed into a $50-\mathrm{ml}$ centrifuge tube with $12 \mathrm{ml}$ of distilled water and blended for $1 \mathrm{~min}$ with a Brinkmann Polytron homogenizer (Westbury, N.Y.) until smooth. $\mathrm{pH}$ and soluble solids of the ground material was determined. Three drops of the liquid were placed on an Atago PR-1 Brix-meter digital refractometer for soluble solids determination. Peel color was evaluated subjectively by comparing fruit with color plates (Chiquita Brands, n.d.) A starch-iodine staining solution of $1.0 \%$ potassium iodide and $0.1 \%$ iodine (Saltveit and Hale, 1982) in distilled water was used. A fresh cross-sectional cut was made across the center of the unpeeled banana, and the cut surface of the blossom end of the banana was allowed to sit at a depth of $5 \mathrm{~mm}$ in the staining solution for 3 to $5 \mathrm{~min}$. Bananas then were rated according to the chart developed previously (Fig. 1). Peel color, soluble solids, and $\mathrm{pH}$ were correlated with the starch-iodine rating, and regression lines or curves were

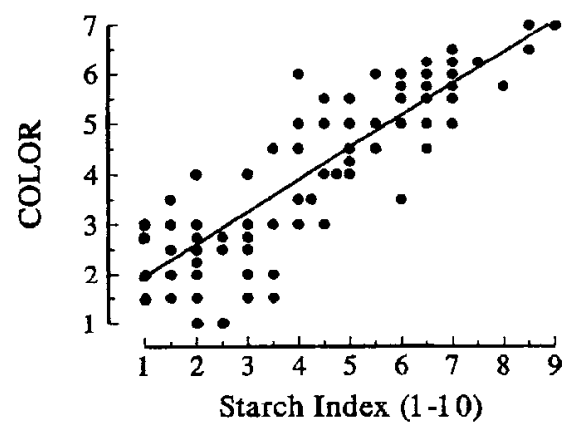

Fig. 2. Relationship of peel color rating to starch-iodine rating in ripening bananas. $y$ $=1.38(x)+0.64, \mathrm{r}^{2}=0.76$.

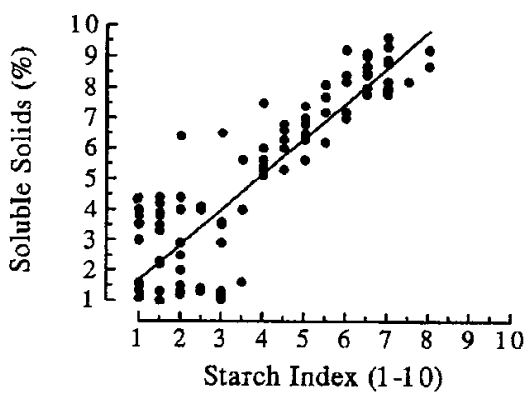

Fig. 3. Relationship of pulp soluble solids content to starch-iodine rating in ripening bananas. $y=0.81(x)+1.16, \mathrm{r}^{2}=0.81$.

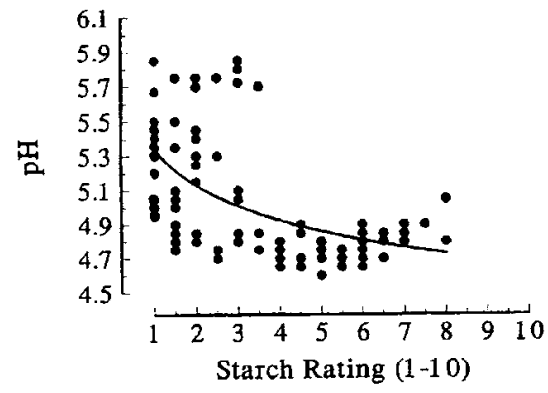

Fig. 4. Relationship of pulp $p H$ to starchiodine rating in ripening bananas, $y=$ $5.34(x)^{-0.06}, \mathrm{r}^{2} 0.38$.

fit to the data of individual bananas obtained from at least three different banana shipments.

Bananas show a characteristic pattern of starch loss during ripening (Fig. 1). The starch stains a blue-black color, while areas that have lost starch remain white. Starch is lost from the center of the banana outward. The relationship between peel color and starch index, according to our chart, shows a reasonable positive linear correlation (Fig. 2 ). The color chart stops at a \#7, which is yellow, flecked with brown. The starch chart continues beyond a color \#7, to the equivalent of an almost black banana. Individual points show that there is variation in starch degradation, particularly as the banana starts to ripen. Soluble solids content and starch index also show a positive linear correlation (Fig. 3). The relationship between $\mathrm{pH}$ changes and starch index is not linear, and best fits an exponential curve (Fig. 4). During normal banana ripening, the starch-iodine staining technique for assessing pulp ripe- ness correlates well with color and soluble solids. Use of the technique to evaluate pulp maturity should be of value to both researchers and workers in the banana industry in evaluations when internal ripeness is more important than appearance, when color is not a usable index, or when temperature and humidity problems arise and external and internal ripening are not well-correlated.

\section{Literature Cited}

Beaudry, R.M., R.M. Severson, C.C. Black, and S.J. Kays. 1989. Banana ripening: Implications of changes in glycolytic intermediate concentrations, glycolytic and gluconeogenic carbon flux, and fructose 2,6-bisphosphate concentration. Plant Physiol. 91:1436-1444.

Charles, R.J. and M.A. Tung 1973. Physical, rheological and chemical properties of bananas during ripening. J. Food Sci. 38:456-459.

Chiquita Brands, Inc. (n.d.) Your guide to greater profits. Chiquita Brands, Cincinnati, Ohio.

Haard, N.F. and H.O. Hultin. 1969. Abnormalities in ripening and mitochondrial succinoxidase resulting from storage of preclimacteric fruit at low relative humidity. Phytochemistry 8:2149.

Hubbard. N.L., D.M. Pharr, and S.C. Huber. 1990. Role of sucrose phosphate synthase in sucrose biosynthesis in ripening bananas and its relationship to the respiratory climacteric. Plant Physiol. 94:201-208.

North, C.J. 1961. Storage and ripening of pears. Annu. Rpt. Ditton \& Covent Garden Labs for 1959 and 1960.

Saltveit, M.E., Jr., and S.A. Hale. 1982. Determining the maturity of North Carolina apples. North Carolina Agr. Ext. Bul. AG-282.

Von Loesecke, H. W. 1950. Bananas. 2nd ed. Interscience, New York. 